\title{
Seven Years of Teaching Communication With the Patient- Centered Observation Form
}

Patricia Adam, MD, MSPH; Courtney F. Murphy; Mary Dierich, PhD, MSPH; Keri D. Hager, PharmD

BACKGROUND AND OBJECTIVES: For years, family medicine has taught patient-centered communication through observations and observation checklists. We explored the utility of one checklist, the Patient-Centered Observation Form (PCOF), to teach and evaluate patient-centered communication in our family medicine residencies.

METHODS: We conducted a mixed-method study of five University of Minnesota Family Medicine Residencies' seven years of experience teaching and evaluating residents' patient-centered communication skills. All programs have a behavioral health $(\mathrm{BH})$ faculty-led observation curriculum that uses the PCOF to assess resident skills and give feedback. We conducted a $\mathrm{BH}$ faculty focus group and interviews, generated themes from the $\mathrm{BH}$ responses, and then queried family medicine (FM) faculty regarding these themes through an online survey.

RESULTS: Ten BH faculty participated in the focus group/interviews, and $71 \%$ (25/35) of FM faculty completed the survey about themes derived from the $\mathrm{BH}$ interviews. The residencies complete between 1 to 11 observations per resident per year. Since implementation, four programs have continuously used the PCOF due to its versatility, design as a formative rather than summative feedback tool, and relative ease of use. BH faculty believe longitudinal observations with the PCOF resulted in improved resident patient-centered communication. Most importantly, all faculty described a shift in family medicine culture toward patient-centered communication. Time for observations and feedback is the primary curricular barrier.

CONCLUSIONS: Our findings support the utility of the PCOF for teaching and evaluating patient-centered communication in family medicine training.

(Fam Med. 2018;50(2):132-7.)

doi: 10.22454/FamMed.2018.516713

n 2013, the medical specialties defined milestones residents should achieve to demonstrate competency. For the primary care specialties, those milestones include patient-centered communication behaviors. Therefore, the Accreditation Council on Graduate Medical Education (ACGME) strongly recommends tool to help teach patient-provider communication. ${ }^{6,7}$

Despite limited reliability data, the most commonly used observation tool for teaching patient-centered communication skills in family medicine is the Patient-Centered Observation Form (PCOF). ${ }^{7}$ The PCOF is a two-page checklist that breaks down the patient visit into well-defined components that are supported by measurable, discrete clinician behaviors. ${ }^{8-10}$

In 2009, the University of Minnesota Department of Family Medicine and Community Health (UMNDFMCH) charged its residency programs to implement a patientcentered communication curriculum using the PCOF. ${ }^{8-10}$ Although the PCOF is one of the most commonly used forms used for assessing patient-centered communication, there is limited published data on how programs have implemented use of the PCOF and its impact on resident communication skills. We conducted a mixed-methods study aimed at characterizing the experiences of five residency programs over 7 years of PCOF implementation and use. Our goal was to explore the utility of the ident-patient interactions to assess resident milestone competency. ${ }^{1,2} \mathrm{Re}$ search supports the incorporation of direct observation to teach and assess learner competence in meeting patient communication skills. ${ }^{2-5}$ Family medicine has for many years prioritized resident observation as a
From the Department of Family Medicine and Community Health (Dr Adam), College of Pharmacy, Department of Pharmacy Practice and Pharmaceutical Sciences (Ms Murphy and Dr Hager), and School of Nursing (Dr Dierich), University of Minnesota. 
PCOF to teach and evaluate patientcentered communication in our family medicine programs.

\section{Methods}

The UMN-DFMCH is comprised of eight sponsored or affiliated family medicine residencies. Each residency has one or two behavioral health (BH) faculty.

The PCOF includes 12 skill sets of patient-centered communication behaviors starting with "establishes rapport" and ending with "closure." Each skill is divided into observable elements and is organized as a checklist. The more boxes the observer checks, the more patient-centered the communication. During the study period, the newest version of the PCOF was utilized as it became available (http://courses.washington. edu/pove/files/PCOF_9_27_2013_clinician.pdf).

\section{Phase 1: Behavioral Health}

Faculty Focus Group/Interviews

Seven out of 10 behavioral health (BH) psychologist faculty from five of the UMN-DFMCH residencies participated in a 60-minute focus group exploring their experiences using the PCOF to evaluate and teach patient-centered communication. Participants were asked semistructured questions about the original implementation plan, current use of the PCOF, and successes and barriers in teaching patient-centered communication. The three remaining $\mathrm{BH}$ faculty had 30 45 minute phone interviews using the same questions. The focus group and phone interviews were audio recorded and transcribed verbatim. A single, trained investigator conducted the focus group and interviews. Phase 1 data analysis was informed by the social constructivist version of grounded theory (used when researchers have some a priori experience/knowledge in the qualitative question being asked). ${ }^{11}$ First, each investigator independently reviewed and coded the transcripts. After independent review, investigators then met and reached consensus about emerging themes through an iterative discussion process. Phase $1 \mathrm{BH}$ interview and focus group themes informed development of the Phase 2 family medicine (FM) survey items.

Phase 2: Family Medicine Faculty Survey

Family medicine physician faculty from the five residency programs $(\mathrm{n}=35)$ subsequently completed a 21-item anonymous online survey (5-point Likert scale; strongly agree to strongly disagree) regarding experiences with the PCOF as a training tool. Items included FM faculty training on the PCOF, frequency of use, comfort using the PCOF, perceptions of utility/impact of the PCOF, and questions specific to the PCOF as a tool.

The University of Minnesota Institutional Review Board deemed this study exempt from review.

\section{Results}

Table 1 describes the family medicine residency programs' demographics and their use of the PCOF.

\section{Family Medicine Faculty Survey Findings}

Although, 71\% (25/35) of the FM faculty completed the survey, only $80 \%$ (20/25) had actually completed a PCOF on a resident, usually through video review $(72 \%)$ or direct observation in clinic $(64 \%)$. Only $36 \%$ of the FM faculty had formal training on how to use the form. Despite the lack of training, $80 \%$ of faculty with PCOF experience were comfortable using the form to evaluate residents. Sixty-five percent believed the PCOF improved their effectiveness in teaching patient-centered communication. Twenty-two percent of FM faculty believed they were less competent in teaching patient-centered communication compared to BH faculty, $31 \%$ were not sure how they compared, and $47 \%$ believed they were as competent. Three themes emerged from Phase 1 and informed the Phase 2 survey: (1) a family medicine residency culture shift, (2) PCOF functionality, and (3) barriers to teaching patient-centered communication.

\section{Theme 1: Family Medicine Residency Culture Shift}

$\mathrm{BH}$ and FM faculty described a change in practice since PCOF implementation, evidenced by the adoption of a common language and faculty incorporation of the communication behaviors in direct patient care (Table 2). BH faculty hypothesized that this culture shift was enabled by a clear leadership directive for implementing a standardized patient-centered communication teaching tool, a required number of resident observations, and use of an evidence-based tool for evaluating and providing feedback. BH faculty reported improved resident patientcentered communication.

In terms of physician communication, I feel like, just observationally, they're so much better than they used to be... I feel like the quality of the communication that I see in our resident physicians has improved over that time. (BH Focus Group)

\section{Theme 2: PCOF Functionality}

$\mathrm{BH}$ and FM faculty agreed the PCOF is a useful, relatively easy tool to use, although it is lengthy and at times not culturally appropriate. FM and BH faculty opinions differed regarding tool functionality with the EHR, helpfulness for milestone competency assessment, and whether the tool is evidence-based (Table 3). BH faculty reported the PCOF helped learners and faculty identify specific patient communication issues and improve communication techniques while emphasizing growth along a continuum rather than a "grade." By anchoring feedback to behaviors, $\mathrm{BH}$ faculty noted feedback is more specific and improvement becomes measurable.

$\mathrm{BH}$ faculty described the PCOF as adaptable to different curricular venues (live observations, video reviews, group reviews, self reviews) 
Table 1: Residency Demographics Number and Type of Observations* by Site

\begin{tabular}{|c|c|c|c|c|c|c|c|}
\hline Program & PGY & $\begin{array}{c}\text { Total Video } \\
\text { Reviews per } \\
\text { Resident } \\
\text { per Year }\end{array}$ & $\begin{array}{c}\text { Total Direct } \\
\text { Observation } \\
\text { per Resident } \\
\text { per Year }\end{array}$ & $\begin{array}{c}\text { Mean (Range) } \\
\text { Total PCOFs } \\
\text { Completed per } \\
\text { Resident per Year }\end{array}$ & $\begin{array}{l}\text { Location of } \\
\text { Observations }\end{array}$ & $\begin{array}{c}\text { Program } \\
\text { BH } \\
\text { FTEs }\end{array}$ & $\begin{array}{c}\text { Number of } \\
\text { Residents } \\
\text { (G1/G2/G3) }\end{array}$ \\
\hline \multirow{3}{*}{ A } & 1 & 4 & 7 & $12(8-15)$ & \multirow{3}{*}{$\begin{array}{l}\text { outpatient } \\
\text { \& inpatient }\end{array}$} & \multirow{3}{*}{1.9} & \multirow{3}{*}{$18(6 / 6 / 6)$} \\
\hline & 2 & 4 & 4 & $14(8-19)$ & & & \\
\hline & 3 & 4 & 4 & $11(7-15)$ & & & \\
\hline \multirow{3}{*}{ B } & 1 & 5 & 1 & $8(3-12)$ & \multirow{3}{*}{$\begin{array}{l}\text { outpatient } \\
\& \text { inpatient }\end{array}$} & \multirow{3}{*}{1.3} & \multirow{3}{*}{$30(10 / 10 / 10)$} \\
\hline & 2 & 3 & 0 & $6(2-8)$ & & & \\
\hline & 3 & 2 & 0 & $4(2-6)$ & & & \\
\hline \multirow{3}{*}{$\mathrm{C}$} & 1 & 1 & 0 & $4(2-6)$ & \multirow{3}{*}{$\begin{array}{l}\text { outpatient } \\
\text { \& inpatient }\end{array}$} & \multirow{3}{*}{0.8} & \multirow{3}{*}{$18(6 / 6 / 6)$} \\
\hline & 2 & 1 & 0 & $4(1-7)$ & & & \\
\hline & 3 & 1 & 0 & $3(0-7)$ & & & \\
\hline \multirow{3}{*}{$\mathrm{D}$} & 1 & 1 & 5 & $6(5-10)$ & \multirow{3}{*}{ outpatient } & \multirow{3}{*}{1.8} & \multirow{3}{*}{$24(8 / 8 / 8)$} \\
\hline & 2 & 1 & 5 & $6(4-6)$ & & & \\
\hline & 3 & 1 & 5 & $6(6-7)$ & & & \\
\hline \multirow{3}{*}{$\mathrm{E}$} & 1 & 0 & 4 & 0 & \multirow{3}{*}{ outpatient } & \multirow{3}{*}{1} & \multirow{3}{*}{$15(5 / 5 / 5)$} \\
\hline & 2 & 0 & 4 & 0 & & & \\
\hline & 3 & 0 & 4 & 0 & & & \\
\hline
\end{tabular}

Abbreviations: PGY-Postgraduate year, PCOF-Patient Centered Observation form, BH-Behavioral health

*Note-One direct observation or video review may include multiple patient encounters. Faculty complete one PCOF per patient encounter. Hence the number of PCOFs may be greater than the number of direct observations or video reviews.

Table 2: Family Medicine Culture Shift

\begin{tabular}{|c|c|c|}
\hline Behavioral Health Focus Group Findings & \multicolumn{2}{|c|}{ Family Medicine Faculty Survey Findings } \\
\hline Quotes & Questions & $\begin{array}{l}\text { Responses }(\mathrm{N}=23) \\
\text { Agree/Strongly } \\
\text { Agree N (\%) }\end{array}$ \\
\hline $\begin{array}{c}\text { "And the focus across the [family medicine] faculty } \\
\text { on this being important." } \\
\text { "The whole patient-centered conversation when } \\
\text { the PCOF came, just shot up across our [family } \\
\text { medicine] faculty... I think that is a huge success." }\end{array}$ & $\begin{array}{l}\text { It is important that family medicine } \\
\text { faculty incorporate the patient-centered } \\
\text { communication behaviors in their } \\
\text { patient interactions. }\end{array}$ & $21(91)$ \\
\hline $\begin{array}{l}\text { "We had a structured tool we were using." } \\
\text { "I'm a very powerful advocate for this tool." }\end{array}$ & $\begin{array}{l}\text { It is important to have a tool } \\
\text { for teaching patient-centered } \\
\text { communication skills. }\end{array}$ & $20(87)$ \\
\hline $\begin{array}{c}\text { "It's affected my clinical practice just in terms of how } \\
\text { I structure my visit... mirrors the PCOF more than } \\
\text { it did previously." } \\
\text { “... used the teach-back for sure,... and probably } \\
\text { agenda setting." }\end{array}$ & $\begin{array}{l}\text { I have changed how I communicate } \\
\text { with my patients as a result of using } \\
\text { the PCOF to teach residents patient- } \\
\text { centered communication skills. }\end{array}$ & $13(57)$ \\
\hline
\end{tabular}


Table 3: PCOF Functionality

\begin{tabular}{|c|c|c|}
\hline $\begin{array}{l}\text { Behavioral Health Psychologist } \\
\text { Faculty Focus Group Findings }\end{array}$ & \multicolumn{2}{|c|}{ Family Medicine Physician Faculty Survey Findings } \\
\hline Quotes & Questions & $\begin{array}{c}\text { Responses ( } \mathrm{N}=23 \text { )Agree/ } \\
\text { Strongly Agree N (\%) }\end{array}$ \\
\hline $\begin{array}{l}\text { "I can say with } 99 \% \text { certainty that use of the } \\
\text { PCOF has strengthened our curriculum and } \\
\text { program approach to communication skills } \\
\text { training in our program." }\end{array}$ & $\begin{array}{l}\text { The PCOF is useful for providing } \\
\text { feedback to residents on their patient } \\
\text { centered communication skills. }\end{array}$ & $20(87)$ \\
\hline $\begin{array}{l}\text { "Sometimes when I am giving feedback to } \\
\text { the residents, I feel there is so much on there, } \\
\text { sometimes they get completely overwhelmed by all } \\
\text { the checkboxes, and so I try to...zero in on..." }\end{array}$ & The PCOF is too long. & $16(70)$ \\
\hline $\begin{array}{l}\text { (note: this FM survey question was derived } \\
\text { from } \mathrm{BH} \text { faculty reporting PCOF use without } \\
\text { training) }\end{array}$ & The PCOF is relatively simple to use. & $15(65)$ \\
\hline $\begin{array}{l}\text { "...cultural competency...some patients who prefer } \\
\text { much more directive language and don't want } \\
\text { to be as collaborative...but on the PCOF, they } \\
\text { wouldn't get points for that, where they should, if } \\
\text { it is culturally appropriate." }\end{array}$ & $\begin{array}{c}\text { The PCOF recommended behaviors may } \\
\text { not be patient-centered in some ethnic } \\
\text { cultures. }\end{array}$ & $14(61)$ \\
\hline $\begin{array}{l}\text { "It gave language. Yeah, it gave language." } \\
\text { "I also hear it in the faculty language." } \\
\text { "Our MD faculty in particular. We just hear more } \\
\text { of those types of...words right off the sheet... } \\
\text { patient-centered type of language." }\end{array}$ & $\begin{array}{c}\text { Use of the PCOF in resident training } \\
\text { has created a common language defining } \\
\text { what patient-centered communication } \\
\text { behaviors are. }\end{array}$ & $13(57)$ \\
\hline $\begin{array}{l}\text { "Now when we have milestone review meetings, } \\
\text { we get reports run ...[with] all the comments } \\
\text { together in one place. And so the milestones } \\
\text { that those feed to, we can kind of comment on } \\
\text { those to then make educational decisions for the } \\
\text { residents." }\end{array}$ & $\begin{array}{c}\text { Individual resident PCOF results } \\
\text { are useful in completing resident } \\
\text { communication milestones during CCC } \\
\text { reviews. }\end{array}$ & $10(43)$ \\
\hline $\begin{array}{l}\text { "I mean, we had a structured tool, but I didn't } \\
\text { like it as well, and it was something that was } \\
\text { kind of, self-created and it wasn't...as satisfying. } \\
\text { I really liked the behavioral anchors along the } \\
\text { continuum." }\end{array}$ & The PCOF is an evidence-based tool. & $10(43)$ \\
\hline $\begin{array}{l}\text { "So I have a whole soapbox about well child } \\
\text { checks and physicals, because of how templated } \\
\text { they are with our EMR, and how that seems to } \\
\text { box people into what they need to ask." }\end{array}$ & $\begin{array}{l}\text { The PCOF does not work well with } \\
\text { templated visits like well child visits, } \\
\text { pre-ops and well exams. }\end{array}$ & $7(26)$ \\
\hline
\end{tabular}

and goals (resident or program-directed). They recommended the PCOF be used longitudinally with incorporation into learner portfolios to track individual feedback and promote skill building over time. One $\mathrm{BH}$ participant noted the PCOF lacked advanced patient-centered communication behaviors, did not match milestones well, and was not flexible for all encounters (eg, basic medication recheck vs noncompliant patient with diabetes). Their program stopped using the PCOF and has developed their own checklist.

\section{Theme 3: Barriers to PCOF}

Implementation

Barriers to PCOF implementation are listed in Table 4. Additional barriers noted by $\mathrm{BH}$ faculty included inconsistent faculty training and equipment/logistical barriers. They also noted residents earlier in training, whose priority is to "avoid killing their patient," may not be developmentally ready for communication feedback.

\section{Discussion}

Our findings support the utility of the PCOF for teaching and evaluating patient-centered communication 
Table 4: Barriers to PCOF Implementation

\begin{tabular}{|c|c|c|}
\hline $\begin{array}{l}\text { Behavioral Health Psychologist } \\
\text { Faculty Focus Group Findings }\end{array}$ & \multicolumn{2}{|c|}{ Family Medicine Physician Faculty Survey Findings } \\
\hline Quotes & Questions & $\begin{array}{l}\text { Responses ( } \mathrm{N}=23) \\
\text { Agree/Strongly } \\
\text { Agree N (\%) }\end{array}$ \\
\hline $\begin{array}{l}\text { "[there are] competing demands; it's hard to have } \\
\text { the time to do it." } \\
\text { "Most of the time we get there [6 PCOF per year] } \\
\text { but with the recent changes, with...getting busier... } \\
\text { [it's possible] we're going to fail to meet that goal." }\end{array}$ & $\begin{array}{l}\text { The primary barrier to teaching patient- } \\
\text { centered communication is the lack of } \\
\text { faculty time for observations or reviews. }\end{array}$ & $17(74)$ \\
\hline $\begin{array}{l}\text { "A couple of groups of residents loved it [PCOF]... } \\
\text { and another [group] were practically hissing at it." }\end{array}$ & $\begin{array}{c}\text { Most residents value being observed (live } \\
\text { or via video review) using the PCOF to } \\
\text { guide the review. }\end{array}$ & $13(57)$ \\
\hline $\begin{array}{l}\text { "Just getting past resident angst and anxiety about } \\
\text { being observed. I'm telling you, 'you're gonna be } \\
\text { recorded, it's part your training.' You know, so- } \\
\text { you can't let them dodge, because their anxiety will } \\
\text { sometimes get in the way." }\end{array}$ & $\begin{array}{l}\text { A significant barrier in improving resident } \\
\text { patient communication skills is resident } \\
\text { anxiety at being observed. }\end{array}$ & $10(43)$ \\
\hline $\begin{array}{l}\text { "Another barrier...sometimes personality types get } \\
\text { so stuck on the paper, the score and the grade... } \\
\text { that you lose track of this conversation we are } \\
\text { having about feedback" }\end{array}$ & $\begin{array}{l}\text { Some residents feel bad if they don't score } \\
\text { a " } 3 \text { " in most components of the form. }\end{array}$ & $5(22)$ \\
\hline
\end{tabular}

in family medicine training. As we discovered, use of an appropriate, ${ }^{12,13}$ established tool consistently over an extended period of time ${ }^{2,14}$ is important. Since implementation in 2009, four of the five programs have continuously used the PCOF due to its versatility, design as a formative rather than summative feedback tool, and relative ease of use. Despite inconsistent training on the PCOF form, $\mathrm{BH}$ faculty believe longitudinal observations resulted in improved resident patient-centered communication, and FM faculty believe they are more effective teaching and comfortable evaluating patient-centered communication behaviors. Most importantly, faculty described a shift in family medicine residency culture toward patient-centered communication. As cited frequently in the literature, the primary barrier for PCOF implementation was time. , $^{2,3,5,7,12,15}$ The literature supports our findings of learner anxiety and grade focus over skill focus, ${ }^{3,9,16,17}$ along with the need for consistent faculty training ${ }^{2,8,9,16}$ as ongoing barriers.
Study strengths include the mixed-methods design and incorporation of both $\mathrm{BH}$ and FM faculty perspectives, perspectives that often concurred, thus reinforcing the findings.

This study was limited to five programs in one family medicine department, thus findings may not be generalizable.

Future research is needed to assess the long-term effect of patientcentered communication training on patient satisfaction and health outcomes. ${ }^{1,18}$

ACKNOWLEDGMENTS: Prior Presentations: Best practice recommendations teaching residents patient-centered communication. Presented at Society of Teachers of Family Medicine Annual Spring Conference, Minneapolis, May 2, 2016.

CORRESPONDING AUTHOR: Address correspondence to Dr Adam, Smiley's Family Medicine Clinic, 2020 East 28th St, Minneapolis, MN 55407. 612-343-7123. Fax: 612-333-1986 adamx005@umn.edu.

\section{References}

1. Kogan JR, Holmboe ES, Hauer KE. Tools for direct observation and assessment of clinical skills of medical trainees: a systematic review. JAMA. 2009;302(12):1316-1326

2. Hauer KE, Holmboe ES, Kogan JR. Twelve tips for implementing tools for direct observation of medical trainees' clinical skills during patient encounters. Med Teach. 2011;33(1):27-33.

3. Donato AA. Direct observation of residents: a model for an assessment system. Am J Med. 2014;127(5):455-460

4. Levinson W, Lesser CS, Epstein RM. Developing physician communication skills for patient-centered care. Health Aff (Millwood). 2010;29(7):1310-1318

5. Carr S. The Foundation Programme assessment tools: An opportunity to enhance feedback to trainees? Postgr Med J. 2006;82(971):576-579.

6. Epstein RM, Street RL Jr. The values and value of patient-centered care. Ann Fam Med. 2011:9(2):100-103

7. Jansen KL, Rosenbaum ME. The state of communication education in family medicine residencies. Fam Med. 2016;48(6):445-451.

8. Chesser A, Reyes J, Woods NK, Williams K, Kraft R. Reliability in patient-centered observations of family physicians. Fam Med. 2013;45(6):428-432

9. Ross V, Mauksch L, Huntington J, Beard JM. Interdisciplinary direct observation: impact on precepting, residents, and faculty. Fam Med. 2012:44(5):318-324. 
10. Keen M, Cawse-Lucas J, Carline J, Mauksch L. Using the Patient Centered Observation Form: evaluation of an online training program. Patient Educ Couns. 2015;98(6):753-761.

11. Charmaz K. Constructing grounded theory. 2nd ed. London, UK: Sage; 2014

12. Gigante J, Swan R. A simplified observation tool for residents in the outpatient clinic. $J$ Grad Med Educ. 2010;2(1):108-110.

13. King A, Hoppe RB. "Best practice" for patientcentered communication: a narrative review. J Grad Med Educ. 2013;5(3):385-393.
14. Kogan JR, Holmboe ES, Hauer KE. Tools for direct observation and assessment of clinical skills of medical trainees: a systematic review. JAMA. 2009;302(12):1316-1326

15. Mahdi Hazavehei SM, Karimi Moonaghi H, Moeini B, Moghimbeigi A, Emadzadeh A. Investigating the key factors in designing a communication skills program for medical students: a qualitative study. Electron Physician 2015;7(7):1441-1448.

16. Edwards A, Tzelepis A, Klingbeil C, et al. Fifteen years of a videotape review program for internal medicine and medicine-pediatrics residents. Acad Med. 1996;71(7):744-748.
17. Pelgrim EAM, Kramer AWM, Mokkink HGA, van der Vleuten CPM. The process of feedback in workplace-based assessment: organisation, delivery, continuity. Med Educ. 2012;46(6):604612.

18. Hudon C, Fortin M, Haggerty J, Lambert M, Poitras M-E. Measuring patients' perceptions of patient-centered care: a systematic review of tools for family medicine. Ann Fam Med. 2011;9(2):155-164. 